\title{
La inevitable inconsistencia del Zeus/Júpiter épico ${ }^{1}$
}

\author{
Cecilia CRIADO \\ Universidad de Santiago de Compostela \\ cecilia.criado@usc.es
}

Recibido: 20 de abril de 2015

Aceptado: 16 de julio de 2015

\section{RESUMEN}

Durante años la investigación literaria ha encontrado fruición en buscar y encontrar inconsistencias narrativas en la Tebaida de Estacio. Concretamente, hay cierto grado de consenso respecto a que las incongruencias en que incurre Júpiter son debidas a negligencia o incuria por parte del poeta. De hecho, no se puede negar que el soberano del cielo se contradice en las ocasiones en que alude a su relación con el Destino. No obstante, no será únicamente el poeta flavio el objeto de mi atención en este artículo. Hoy día se continúa acudiendo a la autoridad filosófica de Séneca (fundamentalmente a Dial. 1.5.8) siempre que el Zeus/Júpiter poshomérico (también el virgiliano) incurre en lo que hemos dado en considerar «incoherencias». Sin embargo, excepción hecha de las composiciones hesiódicas, el estatuto teológico de Zeus/Júpiter es altamente inestable en toda la tradición literaria griega y romana. Quizá deberíamos aceptar, entonces, que durante siglos los que estudiamos literatura antigua hemos tendido a prescindir de la voz autorial y de su autoridad omnímoda para manipular el material literario preexistente con el objeto de generar nuevos significados y nuevas cosmovisiones. En definitiva, nos hemos mostrado proclives a calificar de inconsistencias todo aquello que no se adecua a nuestras expectativas o prejuicios.

Palabras clave: Ambigüedad. Inconsistencia. Destino. Cronología mítica. Épica griega. Épìca flavia.

Criado, C., «La inevitable inconsistencia del Zeus/Júpiter épico», Cuad. Fil. Clás. Estud. Lat. 35.2 (2015) 263-277.

\section{The inevitable inconsistency in epic Zeus/Jupiter}

\begin{abstract}
For years scholars have plunged headlong into looking for inconsistencies in Statius' Thebaid and, obviously, they have found them profusely. Specifically, there is a degree of critical consensus that the inconsistent image of the Statian Jupiter are due to the poets' negligence or carelessness. And, in fact, there is no denying that Jupiter contradicts himself in the Thebaid on those occasions when he alludes to his relationship to Fate. Nontheless, the Flavian poet will not be the sole object of my attention in this paper. Contemporary scholarship has a tendency to bring up Seneca's theories (Dial. 1.5.8) whenever the post-Homeric Jupiter (even the Virgilian one) touches on what has come to be seen as an «incoherence».
\end{abstract}

\footnotetext{
${ }^{1}$ Una versión abreviada de este artículo fue presentada en la reunión de investigadores Unity and Inconsistency in Flavian Epic (dirs. D. Kozák y A. Ferenczi), celebrada en Budapest el 4 y 5 de septiembre de 2014. Mi agradecimiento a los allí presentes por sus sugerencias
} 
However, except for the Hesiodic epics, Zeus/Jupiter's theological status is as unstable throughout the Greek literary tradition as in Statius. Hence, we should accept that, during centuries, the classical scholarship has forgotten the narrative authority and its power to manipulate pre-existing material in order to create new meanings and worldviews. Perhaps we, interpreters of ancient literature, have a tendency to interpret as inconsistences all those facts which do not meet our own expectations or prejudices.

Keywords: Ambiguity. Inconsistency. Destiny. Mythic chronology. Greek epic. Flavian epic.

Sumario: 1. Introducción. 2. La ambigua supremacía de Júpiter sobre el fatum en la Tebaida. 3. Sic fata mihi nigraeque sororum/ iurauere colus. El poder de las Parcas. 4. La presión del sistema literario. La ambigüedad de Júpiter como legado. 5. Conclusión. 6. Referencias bibliográficas.

\section{INTRODUCCIÓN}

Aunque muchos de los que estudiamos hoy día disciplinas humanísticas carecemos de esa natural inmediación con los avances científicos que, en cambio, poseían los hombres de letras del Renacimiento, los descubrimientos científicos inevitablemente permean nuestras mentes. Sucedió durante el auge del estructuralismo y sigue sucediendo ahora, en pleno "posposmodernismo». Nunca antes se había sabido tanto sobre el cerebro humano como en la actualidad. La neurociencia está demostrando que, aunque el cerebro tiende a ser inflexible, son las neuronas del inconsciente las que mayor espacio ocupan en el cerebro y las que realmente rigen los actos de elección (véanse las conclusiones al respecto de John Bargh -Universidad de Yale- y de Tali Sharot -University College London-, por citar dos ejemplos conspicuos). Por tanto, parece que no es aventurado asegurar que todo producto humano (no sólo el signo lingüístico) es arbitrario y, consiguientemente, la incoherencia y la ambigüedad le son consustanciales. De hecho, el recurso a la polifonía, a las further voices, está recobrando nuevo vigor en la crítica de la literatura antigua tras su ya lejana implantación por parte de la Escuela de Harvard en los años sesenta del siglo pasado (Parry 1963, Clausen 1964, Putnam 1965, Lyne 1987). Quiere esto decir que hay una tendencia creciente no sólo a conferir carta de legalidad a la presencia de la ambigüedad e inconsistencia en las obras literarias, sino a considerarlas susceptibles de ser deconstruidas. En contrapartida, se produce un cierto cortocircuito en el círculo hermenéutico pero, me temo, eso es algo contra lo que los que trabajamos en literatura no podemos luchar. En este sentido, O'Hara hace toda una declaración de principios en la introducción de su sugestiva monografía Inconsistency in Roman Epic. Studies in Catullus, Lucretius, Vergil, Ovid and Lucan. Alerta sobre el riesgo de recurrir a la enmienda textual siempre que una inconsistencia es detectada en los textos antiguos. O'Hara propone, en cambio, el reto de someterla a interpretación (O'Hara 2007, p.1).

Lo cierto es que, mientras los especialistas en literatura romana han tendido a ser condescendientes con los fallos compositivos y contradicciones de Virgilio (incluso con los de su muy pulida Geórgicas, cuyas irreconciliables ambivalencias, sin embargo, ya Conington notó [1858, p.4]), la inconsistencia de ciertos pasajes de la Tebaida de Estacio y las fluctuaciones de su voz narrativa han sido denostadas durante años. 
No obstante, aunque no de manera absolutamente unánime, el sentir crítico sobre el poeta flavio ha ido evolucionando a partir de las dos últimas décadas del siglo pasado. No es casualidad que esta revalorización del poeta flavio haya coincidido con el declive de la dictadura cultural del estructuralismo y con el reconocimiento de las fisuras de su «sueño positivista». Ello ha cristalizado en una general rehabilitación y reivindicación de la inconsistencia humana y, por tanto, también de la de Estacio. Así, Hill (2008, p.141) sostiene que los fallos en que incurre el soberano del Olimpo en su primer discurso de la Tebaida no se deben a un descuido compositivo del poeta sino a la «weakness and stupidity of Jupiter». Su aserto es provocativo pero, realmente, hemos de admitir que Estacio es «far too sophisticated to be criticised [al menos gratuitamente] for inconsistency» (Smolenaars 2008, p.237). Como en el caso de otros muchos autores antiguos, en más de una ocasión las inconsistencias de Estacio están retóricamente programadas.

\section{LA AMBIGUA SUPREMACÍA DE JÚPITER SOBRE EL FATUM EN LA TEBAIDA}

En dos trabajos recientes (Criado 2011, 2013), he tratado cuestiones tocantes a la teología épica griega y romana; en ellos apuntaba las cuatro ocasiones en que, en la Tebaida de Estacio, tanto la persona narrativa como Júpiter incurren en contradicción cuando manifiestan la relación del padre de los dioses con el Fatum:

1) En la asamblea divina, Estacio atribuye a Júpiter el estatus de soberano del Destino. Así, graue et immutabile sanctis / pondus adest uerbis, et uocem Fata sequuntur (1.212-213).

2) Siguen las súplicas de Juno para que su marido no haga de la ciudad de Argos el objeto de su cólera. En su réplica, las palabras de Júpiter son consistentes con las del precedente pasaje: Stygia aequora fratris, / obtestor, mansurum et non reuocabile uerbum, / nil fore quod dictis flectar (1.290-292). En definitiva, tanto el poeta como Júpiter consienten en que es la uox del dios la que establece el Destino inmutable en el momento mismo de su acto de habla. Indudablemente, el poder de actuación del dios estaciano es patente pues acto seguido afirma que certo reliqua ordine ducam (1.302).

Estos dos pasajes parecen presagiar un firme posicionamiento teológico por parte del poeta y de Júpiter. No obstante, este último menciona su relación con el Fatum en otras dos ocasiones:

3) El padre de los dioses consuela a Marte, progenitor de la casa de Tebas, de los males que su ciudad está sufriendo. Afirma que los acontecimientos son debidos a los dictados de los Fata y de las Parcas, y que su cumplimiento está establecido desde el comienzo de los tiempos: sic Fata mihi nigraeque Sororum / iurauere colus: manet haec ab origine mundi / fixa dies bello (3.241243). Parece, pues, que Júpiter acepta ahora su subordinación a estas figuras del Destino. 
4) El dios vuelve a reafirmar su sujeción al Fatum en la escena en que conforta al tebano Baco. Júpiter sentencia que no es el resentimiento personal el que lo induce a sacrificar al pueblo tebano, sino que immoto deducimur orbe / Fatorum (7.197-198). Al declararse subditus Fatis (cf. LACT. ad loc.), Júpiter dice no dictar el Destino sino asegurar su cumplimiento. Ni él ni ninguna otra deidad podrá modificar la estoica series Fatorum.

Obviamente, si comparamos los pasajes 1 y 2 con 3 y 4, «apparet poetam non magis quam multos ante eum claram opinionem habuisse de inextricabili ratione quae inter Iovem et Fata intercedit» (Heuvel 1932, p.138). Es más, a lo largo de la composición también varía la opinión al respecto tanto de los personajes humanos como de los divinos. Mientras en unas ocasiones Júpiter es situado en un plano de supremacía universal, en otras es presentado como coejecutor del Destino. De hecho, es constante en la poética estaciana el énfasis que la persona narrativa, los dioses y los mortales hacen sobre su imposibilidad de discernir cuál es la fuerza que gobierna el Fatum ${ }^{2}$.

Como es sabido, con el fin de salvar estas incongruencias narrativas, la mayoría de los estudiosos recurren a la aporética sentencia que Séneca traduce de Zenón (SVF I 162) en Dial.1.5.8.8-9 (véanse también Epist.119.15.4-5, Benef.6.23.1.1-2.1, Nat.2.35.2.7-8). En este pasaje un Séneca estrictamente estoico atribuye a Júpiter la capacidad de scribere Fatum. Introduce, no obstante, una importante y problemática precisión, inspirada, aunque de forma libre, en Zenón: en el momento mismo en que el dios dicta el Destino, él mismo queda para siempre sujeto a él (ille ipse omnium conditor et rector scripsit quidem Fata, sed sequitur; semper paret, semel iussit). El filósofo mantiene que Júpiter dispuso el destino una vez y para siempre, y que desde entonces él mismo obedece su propio decreto; es decir, es ley para sí mismo (Criado 2011, pp.265-266; 2013, pp.206-208). Existe un amplio consenso crítico de que es ésta la noción filosófica que subyace al texto estaciano y la que aclara las contradicciones en que Estacio y otros poetas incurren en su inextricable presentación de la relación de Júpiter con el Destino ${ }^{3}$. De hecho, desde Heinze (1993 [1903], p.237), los estudiosos han recurrido a la máxima senecana para intentar explicar las fluctuaciones de Virgilio $^{4}$ y Lucano ${ }^{5}$ al respecto. Ya en otras ocasiones he mostrado mi reserva

\footnotetext{
2 Tal es lo que ocurre en Theb.1.178-185, 1.326-328, 2.20-22, 2.540, 3.60-62, 3.67-69, 3.241-242, 3.304$307,3.483-488,3.553-555,4.671-672,4.756-758,6.942-944,7.809-817,10.162-163,10.831-836,11.188-$ $189,11.462-463,11.617-620,11.637-638,12.338,12.420-423$.

3 Véanse Legras (1905, pp.168-169), Heuvel (1932, p.101), Snijder (1968, p.125), Vessey (1973, p.83), Schetter (1960, p.29), Thuile (1980, p.222), Adamini (1981, p.24), Billerbeck (1986, pp.3129-3130), Ripoll (1998, p.312), Delarue (2000, pp.295-296), Groß (2003, p.23). Dos interesantes excepciones son Dominik (1994, p.28) y Río Torres-Murciano (2011, p.204).

${ }^{4}$ Sobre las vacilaciones de Virgilio, $c f$. infra n. 15 .

${ }^{5}$ Lucano, aunque con una cautela que queda de manifiesto por la utilización del pleonachos tropos, se hace eco de la sentencia senecana (Siue parens rerum, cum primum informia regna / materiamque rudem flamma cedente recepit, / fixit in aeternum causas, qua cuncta coercet / se quoque lege tenens, et saecula iussa ferentem / fatorum inmoto diuisit limite mundum, 2.7-11). No obstante, también muestra su incerteza de si el Destino predeterminado existe o no antes del acto enunciativo de Júpiter (siue canit Fatum seu, quod iubet ille canendo, / fit Fatum, 5.92-93).
} 
y cautela respecto a la utilización de textos filosóficos para dilucidar la interpretación de productos de ficción. Incluso veo factible (aunque no altamente probable) que, en el caso que nos ocupa, el proceso haya sido el inverso. Es un hecho que, cuando Séneca dice que la deidad suprema semper paret, semel iussit, conculca la ortodoxia estoica por la simple razón de que la doctrina estoica no concibe la Providencia y el Destino en términos de sucesión temporal; no admite un antes y un después (Setaioli 2006-2007, p.361). Podría sugerirse, pues, que la ambigüedad inherente y consustancial al Zeus/Júpiter literario grecorromano (no sólo al estaciano) fue la causa, quizá inconsciente, de la infracción del dogma estoico por parte de Séneca.

\section{SIC FATA MIHI NIGRAEQUE SORORUM /IURAVERE COLUS. EL PODER DE LAS PARCAS}

Mi interpretación de que en los versos 241-243 del libro tres de la Tebaida (cf. supra el pasaje 3) Júpiter efectivamente establece su subordinación al Fatum ha sido recientemente objeto de ciertas puntualizaciones por parte de algunos colegas. Con razón se me ha advertido que iurauere puede ser entendido de dos maneras: un superior (nigrae Sorores) puede informar a un inferior (Júpiter) sobre sus planes preestablecidos, que es lo que yo sostengo; pero un inferior (nigrae Sorores) puede igualmente jurar a un superior (Júpiter) que ha ejecutado o ejecutará aquello que él les ha ordenado. Sin duda, afirman mis críticos, es más factible que las Parcas hayan jurado llevar a efecto el plan dispuesto por Júpiter.

Las traducciones que los especialistas ofrecen de estos tres versos son de poca ayuda ya que prudentemente no aventuran una interpretación del texto ${ }^{6}$. Únicamente Shackleton Bailey proporciona evidencia de que el -que de nigraeque es epexegético; esto es, queda claro que Bailey entiende que el Destino y las Hermanas son una única entidad: «Thus the Fates, the dark distaffs of the Sisters, have sworn to me». En cuanto a crítica textual se refiere, la mayoría de los editores aceptan la lectura de los códices, iurauere colus. Dos excepciones son Servio (ad Aen.8.409) y Garrod (1965 [1906]), que leen lustrauere, verbo que no ofrece un sentido claro. En la innovadora y arriesgada edición de Hall, Ritchie y Edwards (2008) aparece ius neuere. La traducción sería, entonces, «ellas [las Parcas] hilaron la autoridad [de Júpiter]». Aceptan, pues, la conjetura que Hall había propuesto en los años noventa del siglo pasado y que, en su opinión, era procedente, pues «how can distaffs 'swear'?» (Hall 1992, p.61). No obstante, a mi modo de ver, la corrección del texto no es necesaria, e innecesariamente deja sin efecto el ingenio de la metonimia.

Es evidente que si forzamos a que el texto diga «los Destinos/las Parcas hilaron la autoridad de Júpiter», conseguimos que este pasaje sea congruente con aquellos

\footnotetext{
${ }^{6}$ Para citar únicamente algún ejemplo, Mozley (1928) traduce «Thus have the Fates sworn to me, and the dark spindles of the Sisters», Joyce (2008), «Fate and the Sisters' dismal spindle have thus sworn to me»y Micozzi (2010), «Me l'hanno giurato i Destini e le nere conocchie delle sorelle fatali».
} 
otros en que Júpiter aparece como soberano absoluto del Hado (véanse los textos 1 y 2 , citados supra). Sin embargo, en mi opinión, éste es un buen ejemplo de hasta qué punto la presuposición de coherencia puede afectar a la práctica editorial. También evidencia que todavía hoy día sigue siendo difícil «to accept the fallibility [y, añadiría yo, la irracionalidad inherente a la libertad de la labor creativa] of the ancients authors» (De Beer 2013, p.336). Estoy razonablemente segura de que, con sic Fata mihi nigraeque Sororum / iurauere colus: manet haec ab origine mundi / fixa dies bello (3.241-243), Júpiter no afirma que las Parcas juraron ejecutar un plan que él les había ordenado. Lo que ellas juran al padre de los dioses es que la guerra fratricida entre Eteocles y Polinices está decidida por el Destino desde los orígenes del mundo. De hecho, en los textos clásicos conservados, las Parcas hilan stamina, fatalia stamina, fila o, incluso, su propia lex (TiB.1.7.1-2; Ov.Met.8.453; Tr.5.3.25). Nunca, sin embargo, hilan una orden, un decreto, un mandato o el ius de un dios o de un humano. Con todo, hay que reconocer a favor de la conjetura de Hall que, aunque las Parcas hacen promesas en alguna ocasión (VERG.Aen.9.107; Ov.Ib.243; STAT.Theb.7.774), es muy raro que juren. No obstante, ello sucede en dos ocasiones en la literatura romana conservada y ambas ocurren precisamente en Estacio, circunstancia que ha de ser forzosamente significativa tanto a efectos de crítica textual como de interpretación literaria. Estacio es el único autor romano en que las Parcas profetizan el futuro por medio de un juramento, un acto que la tradición mítica reservaba fundamentalmente para Zeus/Júpiter. Lo hacen en el pasaje de la Tebaida que está siendo objeto de atención ahora y lo vuelven a hacer en Silv.5.1.262 (certae iurant in uota Sorores) cuando, haciendo ostentación del mismo poder y autonomía que se les reconoce en Theb.3.241-243, usurpan el gesto de Júpiter y juran cumplir la imploración de Priscila.

Hay otro aspecto de estos tres versos sobre el que interesa detenerse a pesar de que no suscitó el interés de Lactancio, que se limita a indicar que colus significa pen$s a$, ni mereció comentario alguno por parte de Caspar von Barth. Su cabal interpretación, sin embargo, importa, pues podría revelar una nueva incoherencia entre otros dos de los cuatro pasajes en los que, según hemos visto, Estacio o Júpiter se refieren a la relación del soberano del Olimpo con el Destino; concretamente entre el pasaje 1 y el 3. Como ya notó Legras (1905, p.169), hay una incongruencia cronológica pues, si el Destino está fijado desde el principio del Universo (manet haec ab origine mundi, 3.215), no es posible que Júpiter esté dictando el Fatum en el momento mismo de su acto de habla, que es lo que un muy senecano Estacio afirmaba en el verso 213 del libro primero (pondus adest uerbis et uocem Fata sequuntur) ${ }^{7}$. Aunque el siempre certero Feeney (1982, n.22) muestra su acuerdo con Legras, no parece necesario, según veremos, ser críticos tan severos y quisquillosos.

\footnotetext{
${ }^{7}$ En palabras de Legras (1905, p.169): «si les destins sont fixes des le commencement des choses, ils ne suivent donc pas la parole de Jupiter, comme l'assure le poete, et surtout, si ce sont les Parques qui font les Destins, ce n'est donc pas Jupiter».
} 


\section{LA PRESIÓN DEL SISTEMA LITERARIO. LA AMBIGÜEDAD DE JÚPI- TER COMO LEGADO}

Difícilmente se puede negar que tanto la problemática conciliación entre la entidad metafísica y la entidad mítica del dios supremo, como las inconsistencias cronológicas que derivan de ella, estaban ya presentes en los momentos fundacionales del género épico. Hesíodo logra dotar de plena dimensión teológica la realeza mágica de Zeus. ${ }^{8}$ La supremacía de Zeus sobre el destino ${ }^{9}$ es incontrovertible. Él conoce los designios inmortales ( $\alpha \varphi \theta i \tau \alpha \mu \eta ́ \delta \varepsilon \alpha T h .545,550,561, O p .265)$ y no es posible engañar o evitar su vóoৎ (Th.613, Op.105). Es él quien asigna a cada ser humano su lote $(T h .348,520)$ y quien confiere a las Moirai el don de proporcionar felicidad o adversidad a los mortales (Th.906). En ningún pasaje de las composiciones hesiódicas aparece una restricción o reformulación al respecto. No se encuentra ninguna de las ambigüedades que, en cambio, emanan de los poemas homéricos ${ }^{10}$. Sin embargo, en

\footnotetext{
${ }^{8}$ En Teogonia, tras haber alcanzado la hegemonía en el reino de los cielos, Zeus se une con diversas diosas preolímpicas. Reflejando fielmente el sistema dotal helénico, sustrae de sus esposas diversos atributos que, mágicamente, lo capacitan para ejercer la soberanía eternamente (Bermejo, 1996, p.71; cf. también Santamaría Álvarez, 1915, p.68). Citaré sólo dos de estas uniones: de la misma manera que el Cronida adquiere la Ley o el poder jurídico gracias a su unión con Temis, su matrimonio con Metis le confiere la Sabiduria, esto es, el poder mágico de la realeza ( $c f$. González García, 1996, p.228).

${ }^{9}$ Utilizo «destino» en minúscula cuando me refiero a contextos prefilosóficos como es el caso de Homero y Hesíodo.

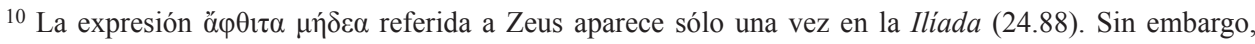
en numerosas ocasiones el dios recibe el epíteto de $\mu \eta \tau i \varepsilon \tau \alpha$, aunque no parece que haya sido del interés de Homero investigar sobre el origen de esta cualidad.

El poder del Zeus homérico adolece de ciertas debilidades que afectan a su relación con las fuerzas del destino. Al igual que el caudillo humano Agamenón ante la asamblea de nobles, el Cronida homérico en ocasiones tiene que negociar sus decretos o, incluso, renunciar a ellos; se ve obligado a tomar decisiones colegiadas y a tener en consideración los intereses de los otros miembros del concilio de dioses (Il.4.14-17, 4.29, 4.37-42, 8.39-40, 16.441-450, 22.181, 24.71, Od.1.76-79). Aun así, podemos aceptar que, en términos generales, la posición constitucional de Zeus permanece constante en las composiciones homéricas, pues es un monarca de poder absoluto. Lo dice él mismo y lo reconocen los otros dioses (por ejemplo, en Il.1.565-567, $1.580-581,1.589,4.55-56,8.12-26,8.31-32,15.107-108,15.128-141$, Od. 5.4).

$\mathrm{Su}$ estatus teológico es, en cambio, altamente inestable. Ya sea porque la Ilíada documenta un estadio más antiguo del pensamiento griego que el autor de la Teogonía, ya sea debido a la mayor complicación argumental de sus composiciones, el hecho es que la relación del Zeus homérico con el destino se resiste a cualquier intento de sistematización. Creo que lo único que se puede afirmar con certeza es que Homero, sobre todo en la Odisea, sugiere una fuerte asociación y, en ocasiones, una total identificación entre Zeus (Zkv̀

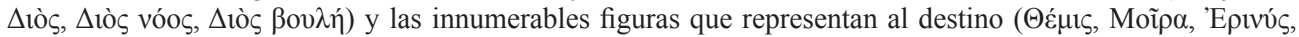
Aĩ $\sigma \alpha$, Kñ $\rho \varepsilon \varsigma, ~ e t c)$. Magris (1985, p.169) advierte que esta indeterminación teológica no ha de sorprender ya que traer a colación la cuestión de si en los poemas homéricos el destino depende de una deidad personal es un «grossolano anacronismo». En su opinión, tal reflexión sólo surgirá cuando la divinidad sea concebida en términos «etico-intellettualistici», y éste es un logro de la Grecia iluminista, no de la arcaica. Hay que consentir que todo ello es cierto. No obstante, en Hesíodo, que comparte con Homero la mentalidad prefilosófica, encontramos a Zeus identificado contundentemente con el orden cósmico del Universo, es decir, con $\Delta$ íkๆ. Esta última noción parece no ser tan tardía como mantuvo Dietrich (1965, pp.212ss.). De hecho, hay indicios de que el concepto de orden cósmico asociado a los dioses estaba ya presente en el mundo micénico y prehelénico (Bermejo Barrera 1996, p.60). Para la presencia, también en Homero, de la justicia de Zeus, $c f$. Lloyd-Jones (1971, p.35), Dicke (1978, pp.91-101), Allan (2006, pp.1-35).
} 
la Teogonía existe un caso de analepsis narrativa que acoge en su seno una «actorial prolepsis» (Nünlist 2007, pp.42-43, n.13) cuyo contenido ha sorprendido a los lectores desde la antigüedad. En esta analepsis proléptica se dice que, tiempo ha, Crono había sabido de boca de Gea que estaba destinado a ser derrocado por su hijo pues tal

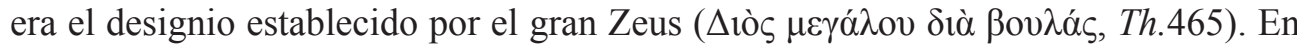
este momento de la narración Zeus, lógicamente, todavía no ha nacido y, consiguientemente, desde la perspectiva de un severo lector antiguo o actual, no es posible que tuviese el poder de decidir el destino de su padre.

Ya el escoliasta notó la contradicción y admitió que algunos preferían leer $\pi \alpha \tau \rho o ́ \varsigma$

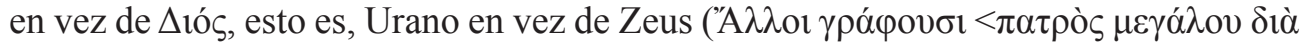

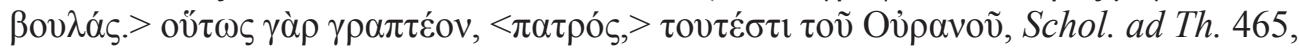
Di Gregorio, p.75). Fue, precisamente, la conciencia del anacronismo lo que indujo a Guyet, Heyne, Wolf y Gaisford a considerar espurio el verso 465 de la Teogonía (Evelyn-White 2008 [1914], p.131) y a otros editores más recientes, sospechoso. Y, en efecto, bien pudiera ser; pero podría tratarse, de nuevo, de un ejemplo más de hasta qué punto en ocasiones la práctica editorial está condicionada por la presunción de que la coherencia narrativa tiene que existir. ${ }^{11}$ Lo cierto es que la inconsistencia de esta frase de Hesíodo, que Magris (1985, p.172) definió como tan cándida como terriblemente audaz, resonará a lo largo de toda la historia de los géneros épico y trágico. Será constantemente traída a colación por los poetas, aunque nunca resuelta.

En realidad, hacia finales del s. V a.C., en su intento de elucidar el sentido de los poemas órficos, las palabras del autor del papiro de Derveni siguen dejando constancia de que cohonestar reflexión especulativa y mitología (o, en este caso concreto, cronología mítica) es una tarea ardua. Asume que los órficos pensaban que la Moira, antigua figura del Destino llamada «sabiduría» por Orfeo, existía antes de Zeus. Sólo recurriendo a una muy intrincada y perpleja argumentación, logra dar una poco satisfactoria explicación al hecho de que los órficos creyesen que Zeus nació cuando recibió su nombre, aunque, aun sin tener nombre, ya existía. Por ello, concluye el autor del papiro, Orfeo dice que «Zeus nació el primero:

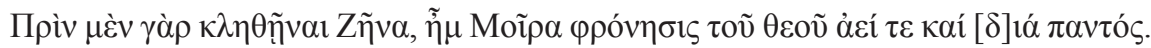

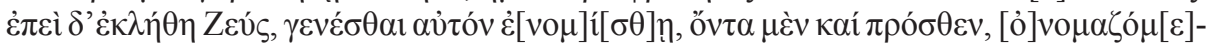

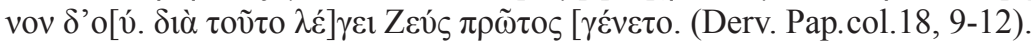

La producción épica romana contemporánea a Estacio continúa documentando las mismas dificultades. Mientras el Júpiter de Silio Itálico parece querer eludir esta ardua cuestión pues en ningún momento menciona su relación con el Destino, el primero de los épicos flavios ofrece amplia y cumplida información al respecto. En

\footnotetext{
${ }^{11}$ Véase el interesante estudio de Wecowski (2012, pp.45-54) sobre la incongruencia presente en el relato hesiódico del engaño de Prometeo a Zeus en el reparto de la carne sacrificial (Th.535-541). Según el estudioso, las enmiendas textuales de los editores posteriores a Guyet que pretendían salvar la contradicción lo que consiguen es impedir la correcta interpretación del pasaje, pues modifican el pensamiento teodiceico que Hesíodo plantea.
} 
la primera asamblea divina de las Argonáuticas de Valerio Flaco, Júpiter declara que él es el conditor del Hado inmutable (uetera haec nobis et condita pergunt / ordine cuncta suo, 1.534; cum Fata darem, 1.531-532). Con una audacia verbal que no tiene precedentes en la épica romana, el dios se atribuye sin ambages la condición de Demiurgo estoico ${ }^{12}$. Su dicción, obviamente, es senecana ${ }^{13}$. Como ya ha sido notado por numerosos críticos entre los que merecen mención especial Stover (2012, pp.36-37) y Feeney (1991, p.281), este Júpiter da una respuesta contundentemente filosófica a las incertidumbres metafísicas que atenazaban a Lucano sobre si el Universo es conducido por el estoico parens rerum $(1.7)^{14}$ o por la no teológica aleatoriedad epicúrea (siue nihil positum est, sed fors incerta uagatur / fertque referque uices et habet mortalia casus, 2.12-13). Siguiendo la senda ya hollada por Ovidio (Met.9.434), las palabras que Valerio pone en boca del summus sator resultan también desambiguar las incertidumbres del propio Virgilio ${ }^{15} \mathrm{y}$, cabría aventurar, del conjunto de la tradición épica y trágica grecorromana. Con claridad perspicua, el dios afirma que su designio abarca la totalidad (cuncta, 1.532) y, lo que es más importante, que permanece inamovible (fixa manent, 1.533 y sed nulla magis sententia menti / fixa meae, 1.548-549) desde el comienzo de los tiempos (rerumque a principe cursu, 1.532).

Ahora bien, el Júpiter de las Argonáuticas está lejos de poder ser fiel a esta sustancia estoica. Y no parece probable que haya sido el propósito de Valerio conjurar los peligros de la vagüedad de su poder corrigiendo la tradición precedente. Al contrario; da la impresión de que el poeta encuentra cierta fruición en que el dios, en su primer discurso y en el solo transcurso de unos versos, muestre acumulativamente todas y cada una de las ambigüedades que su figura exuda a lo largo de toda la documentación literaria grecorromana. Así, sin solución de continuidad, Júpiter se contradice y verbaliza su relación con el Destino en unos términos que prefiguran las

\footnotetext{
${ }^{12}$ Recordemos que cuando Ovidio narra en las Metamorfosis el triunfo del Cosmos sobre el Caos como debido a la agencia de una fuerza identificable con el Demiurgo, se abstiene de nominarla o de identificarla con deidad alguna (Hanc deus et melior litem natura diremit, 1.21, Sic ubi dispositam, quisquis fuit ille deorum, I congeriem secuit, 1.32-33). Incluso, podría ser que Ovidio haya querido sugerir que él mismo fue tal creador divino (Wheeler, 1999, p.30).

${ }^{13}$ Sen.Dial.1.5.8.8-9 (cf. el pasaje supra en p.4), Epist.119.15.4-5. Cf. Billerbeck (1986, pp.3129-3130), Wacht (1991, p.8).

14 Véase el pasaje 2.7-11 supra en n.5.

${ }^{15}$ Citaré únicamente la que considero más flagrante para los efectos que nos ocupan. En el libro primero de la Eneida, Júpiter apacigua los temores de Venus respecto a la fundación de Roma. Afirma que el Destino se mantiene inmutable pues él no ha cambiado de opinión (neque me sententia uertit, 1.260). Acto seguido, se dispone a informar a la diosa sobre el curso del Fatum mediante un acto de habla (fabor, v. 260) que, sin embargo, resulta no ser tal sino un mero ejercicio de recuerdo de unos destinos establecidos en el origen de los tiempos (longius et uoluens Fatorum arcana mouebo, 1.262). Es quizá elocuente que haya sido Ovidio el que saca partido de la discrepancia virgiliana y la resuelve. En las Metamorfosis, Júpiter no pronuncia el destino (cosa que, en cambio, sí hace en STAT. Theb.1.212-213, 1.290-292) ni lo escribe (como en SEN.Dial.1.5.8.8-9) sino que lo lee (legi, 15.814). El dios soberano leyó el Destino de Roma en la mansión de las Parcas y, por ello, puede comunicárselo a Venus. Ovidio ha transformado a Júpiter en un mero pregonero del texto indestructible de los Fata (Feldherr 2010, p.70, Criado 2011, pp.267-269). Para una argumentación más detallada del Fatum virgiliano, $c f$. Criado (2011, n.7 y 16, 2013, p.212). Para las inconsistencias de las profecías de Júpiter en la Eneida, véanse Mack (1978, pp.55-84), O’Hara (1990, pp.132-163, 2007, pp.78-82).
} 
oscuridades estacianas y aglomeran el conjunto de las de los poetas precedentes. En primer lugar, el padre de los dioses sugiere que él no es el amo del Fatum sino que uno y otro son dos fuerzas separadas aunque, como en la Odisea, concurrentes (sic Fata locos, sic ipse fouebam, 1.541). En segundo lugar, contradiciendo su aserto previo de que el rerum cursus está fijado desde el comienzo de los tiempos, declara que será en el futuro cuando conciba sus planes sobre los imperios terrenales (arbiter ipse locos terrenaque summa mouendo / experiar, quaenam populis longissima cunctis / regna uelim linquamque datas ubi certus habenas, 1.558-560).

Como sucedía en los otros autores estudiados en este trabajo, la afirmación de Júpiter de que fue él quien estableció el Destino en el inicio del mundo es problemática desde el punto de vista de la cronología mítica relativa. En el marco narrativo de las Argonáuticas Júpiter es un recién llegado al trono (regni sensit nouitate, 2.83). Es patente el interés de Valerio en que el lector sea consciente desde el comienzo de la composición de que está siendo testigo del «end of the Golden Age, and the beginning of Jupiter's kingdom for mankind» (Feeney 1991, p.330). Júpiter, en efecto, ha inaugurado una nueva era tras usurpar gloriosamente la soberanía a su padre Saturno, cuya ociosidad el nuevo rey de los cielos reprueba (Siderea tunc arce pater pulcherrima Graium / coepta tuens tantamque operis consurgere molem / laetatur; patrii neque enim probat otia regni, 1.498-500). El poeta presenta al dios deleitándose en el gran poder sobre las demás deidades que ahora ostenta (2.82-93) y regodeándose en el recuerdo de los detalles de su triunfo en la lucha por la sucesión del reino de los cielos (Me primum regia mundo / Iapeti post bella trucis Phlegraeque labores / imposuit; durum uobis iter et graue caeli / institui, 1.563-566; Instaurat mensas pacemque reducit / et iam sidereo noctem demittit Olympo. / Tunc adsuetus adest Phlegraeas reddere pugnas / Musarum chorus et citharae pulsator Apollo, / fertque grauem Phrygius circum cratera minister, 5.690-694). Esto, obviamente, no es posible ya que la Edad de Oro había concluido mucho antes de que la expedición de los Argonautas tuviese lugar (Manuwald 1999, pp.151-152). Tampoco es factible que, como miembro de la

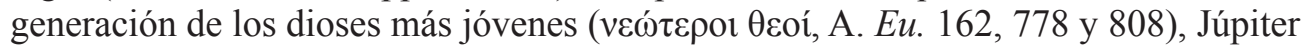
haya podido dictar los Fata en los tiempos primordiales de la creación del mundo.

No obstante, con esta inconsistencia Valerio consigue poner de relieve un hecho de gran trascendencia en la historia del género épico. El poeta demuestra su absoluta conciencia de que, igual que en los tiempos de Hesíodo, el decreto de Júpiter sigue siendo algo mucho más profundo y complejo que la mera personalidad mítica o que la complexión literaria del dios. Como también hará Estacio, el autor de las Argonáuticas muestra cuán irreconciliables son los senderos del primum genus theologiae (VARro Ant.Div.6-11), esto es, de la teología mítica, y los de la naturalis theologia. Aunque tal como sugiere Río Torres-Murciano (2011, p.195), esta incongruencia cronológica pudiera deberse a los intereses narrativos de Valerio ${ }^{16}$, lo cierto es que, sin

\footnotetext{
${ }^{16}$ En opinión del investigador, al hacer que la expedición de los Argonautas coincida con el comienzo del reinado del hijo de Saturno, Valerio consigue su objetivo de que la acción épica se sitúe en un tiempo mítico muy preciso, el de la edad de los héroes, regida por Júpiter.
} 
complejos, Valerio deja constancia de su aquiescencia a las ambigüedades que Júpiter ha heredado de la tradición literaria.

\section{CONCLUSIÓN}

En todo caso, las incongruencias teológicas, mitológicas y de cronología mítica que hemos apuntado difícilmente pudieron haber causado turbación en los lectores antiguos y tampoco deberían causarla en los actuales. Hay indicios de que los lectores antiguos daban pleno consentimiento a las inconsistencias de las composiciones literarias puesto que tal era lo que habían aprendido a esperar de ciertos géneros (O’Hara 2007, p.5). De hecho, con estas premisas analizó Hardie (1987, pp.163171) la negligencia compositiva de Catulo en el poema 64. Como es sabido, el poeta incurre en incoherencia cronológica entre la historia de Ariadna y Teseo que aparece bordada en la uestis, y que implica la navegación a Creta, Día y Atenas, y su propia afirmación de que la expedición de la nave Argo fue la primera navegación de la historia de la Humanidad (illa rudem cursu prima imbuit Amphitriten, v. 11). De forma convincente Hardie demostró que esta presunta incuria no es involuntaria y que con ella el poeta pretendía revisar y reescribir pero, sobre todo, corregir el conjunto de la tradición preexistente sobre las bodas de Peleo y Tetis; y esta transformación del horizonte de expectativa genérica se habría producido con la connivencia del lector $^{17}$. Similares enfoques de estudio han recibido, por ejemplo, las incongruencias narrativas de Virgilio en las Geórgicas (Thomas 1999, pp.128-129; Hardie 1999, pp.68-70) y los deliberados anacronismos e inconsistencias cronológicas de Ovidio en las Metamorfosis (Wheeler 1999, pp.121-139, Zissos y Gildenhard 1999, pp.3147). Prueba de que hoy día esta hermenéutica de la ambigüedad es una perspectiva privilegiada por la investigación de la literatura clásica es que en septiembre de 2014 se celebró en Budapest una reunión de investigadores sobre este tema específico y que en 2016 Arethusa tiene prevista la publicación de un volumen monográfico al respecto.

No quiere esto decir que se deba caer en la simplificación de considerar que todas las inconsistencias narrativas de los autores antiguos fueron fruto de una programación retórica. No obstante, en lo que al estricto campo de la teología literaria se refiere, el análisis del conjunto de la documentación épica y trágica tanto griega como romana deja patente que en casi todos los autores persiste la caótica fisura entre los poderes divinos del Universo que ya presentaban los poemas homéricos (Criado 2013, pp.210-211). Sucede de forma tan pertinaz que sugiere que, a pesar de los esfuerzos de la reflexión filosófica de la Grecia iluminista por superar el pesimismo inherente a la ambigüedad del estatus ontológico del Zeus literario que emanaba de

\footnotetext{
${ }^{17}$ En fechas más recientes, diversos autores han dado su aquiescencia a la interpretación de Hardie. $C f$, por citar algún ejemplo, Jackson (1997, pp.249-257), Weber (1983, pp.263-271), Thomas (1999, p.128), Feeney (2007, pp.124-125).
} 
la religiosidad olímpica arcaica, los poetas optaron mayoritariamente por no desambiguar la indecisión primordial.

Contra lo que sostienen los más firmes partidarios de que el Júpiter estaciano es el amo del Fatum y del mundo moral ${ }^{18}$, la ejecución del plan de los acontecimientos no está sujeto en forma alguna al ordo certus (1.302) que Júpiter proclamaba al inicio de la Tebaida (Reitz 2012, pp.37-38). Ello entra en conflicto con las expectativas de un lector actual que, quizá, deudor inconfeso de los análisis románticos sobre la deidad suprema mitológica hechos por F.W.J von Schelling y F.G. Welcker, parece seguir buscando en la figura de Zeus como divinidad soberana la concepción monoteísta de lo divino (Magris 1985, pp.68-69). Cabe la posibilidad de que la tendencia a considerar fallos compositivos aquellos pasajes en que Zeus/Júpiter se contradice obedezca a la preconcepción de que el Zeus/Júpiter literario es el trasunto del Dios del pensamiento judeo-cristiano, que ostenta el poder supremo y es el soberano indiscutible del mundo moral (Schmidt 2001, p.167). Tal proceder es hermenéuticamente legítimo o, en todo caso, difícilmente evitable, pues ¿acaso no podrían ser las palabras que Isaías pone en boca de Yavhé en 55.11 (sic erit uerbum meum quod egredietur de ore meo non reuertetur ad me uacuum sed faciet quaecumque uolui et prosperabitur in his ad quae misi illud) un imposible pero perfecto hipotexto del aserto de Júpiter en los versos 291-292 del libro primero de la Tebaida (obtestor, mansurum et non reuocabile uerbum, | nil fore quod dictis flectar)?

\section{REFERENCIAS BIBLIOGRÁFICAS}

AdAminI, G. (1981), «La raffigurazione del destino nella Tebaide di Stazio», Anazetesis 4-5, 15-28.

Allan, W. (2006), «Divine Justice and Cosmic Order in Early Greek Epic», JHS 126, 1-35.

Bermejo BARRERA, J.C. (1993), «Mito e historia: Zeus, sus mujeres y el reino de los cielos», Gerión 11, 37-74.

Bermejo Barrera, J.C. (1996), «Zeus, sus mujeres y el reino de los cielos», en Bermejo Barrera, J.C. - Reboreda Morillo, S. - González García, F.J. (eds.), Los orígenes de la mitología griega, Madrid, Akal Universitaria, pp.41-74.

BILLERBECK, M. (1986), «Stoizismus in der römischen Epik neronischer und flavischer Zeit», ANRW 2.32.5, 3116-3151.

Clausen, W. (1964), «An Interpretation of the Aeneid», HSCP 68, 139-147.

Conington, J. (1858), The Works of Virgil with a Commentary, Londres, Whittaker \& Company.

CRIADO, C. (2011), «Teologías y teodiceas épicas. La perspectiva estaciana», Emerita 74.2, 251-275.

CRIADO, C. (2013), «The contradictions of Valerius' and Statius' Jupiter. Power and Weakness of the Supreme God in the Epic and Tragic Tradition», en Manuwald, G. - Voigt, A. (eds.), Flavian Epic Interactions, Berlín, Gruyter, pp.195-214.

\footnotetext{
${ }^{18}$ Así lo defienden Venini (1961, p.74), Gossage (1972, p.203), Vessey (1973, pp.67, 82-86), Franchet d'Esperey (1983, p.101), Ramelli (1999, pp.418-421), Delarue (2000, p.245).
} 
De Beer, S. (2013), «The Survival of Pliny in Padua. The Botanical Renaissance and the Transformation of Classical Scholarship», en ENENKEL, K.A.E. (ed.), Transformations of the Classics via Early Modern Commentaries, Leiden - Boston, Brill, pp.327-362.

Delarue, F. (2000), Stace, poète épique: originalité et cohérence, París, Peeters.

Dicke, M.W. (1978), «Dike as a Moral Term in Homer and Hesiod», CPh 73, 91-101.

Dietrich, B.C. (1965), Death, Fate and the Gods. The Development of Religious Idea in Greek Popular Belief and in Homer, Londres, Athlone Press.

Dominik, W.J. (1994), The Mythic Voice of Statius. Power and Politics in the Thebaid, Leiden, Brill.

Evelyn-White, H.G. (2008 [1914]), Hesiod. The Homeric Hymns, and Homerica, Stilwell, Digireads.com.

FeEney, D.C. (1982), A Commentary on Silius Italicus Book I, Oxford (diss.). http://uts. cc.utexas.edu/cgi-bin/cgiwrap/silver/frame.cgi?silius,style.

FeEney, D.C. (1991), The Gods in Epic. Poets and Critics of the Classical Tradition, Oxford, Clarendon Press.

Feeney, D.C. (2007), Caesar's Calendar: Ancient Time and the Beginnings of History, Berkeley - Los Angeles, University of California Press.

Feldherr, A. (2010), Playing Gods. Ovid's Metamorphoses and the Politics of Fiction, Princeton - Oxford, Princeton University Press.

Franchet-D’Espérey, S. (1983), «Le destin dans les épopées de Lucain et de Stace», en Jounn, F. (ed.), Visages du destin dans les mythologies. Melanges Jacqueline Duchemin, París, Les Belles Lettres, pp.95-104.

Garrod, H.W. (1965 [1906]), P. Papinii Statii Thebais et Achilleis, Oxford, Clarendon Press.

GonZÁLEZ GARCíA, F.J. (1996), «Mito y epopeya: la historia mítica de Aquiles y la Ilíada», en Bermejo Barrera, J.C. - Reboreda Morillo, S. - González García, F.J. (eds.), los orígenes de la mitología griega, Madrid, Akal Universitaria, pp.217-300.

Gossage, A.J. (1972), «Statius», en Dudley, D.R. (ed.), Neronians and Flavians, Londres, Routledge - Kegan Paul, pp.184-235.

Grob, A. (2003), Prophezeiungen und Prodigien in den Argonautica des Valerius Flaccus, München, C.H. Beck.

HaLl, J.B. (1992), «Notes on Statius’ Thebaid Books 3 and 4», ICS 17.1.

Hall, J.B. - Ritchie, A.L. - Edwards, M.J. (2007), P. Papinius Statius. Thebaid and Achilleid, 3 vol., Cambridge, Cambridge Scholars Publishing.

Hardie, P. (1987), «Ships and Ship-names in the Aeneid», en Whitby, M. - Hardie, P. Whitby, M. (eds.), Homo Viator: Classical Essays for John Bramble, Bristol, Classical Press, pp.163-171.

HARDiE, P. (1999), Georgics, Londres - Nueva York, Routledge.

HeInZE, R. (1993 [1903]), Virgil's Epic Technique, Berkeley - Los Angeles - Oxford, University of California Press.

Heuvel, H. (1932), Publii Papinii Statii Thebaidos liber primus, versione batava commentarioque exegetico instructus, Zutphen, Nauta \& Company.

Hill, D.E. (2008), «Jupiter in Thebaid 1 again», en SMOLENAARS, J.J.L. - HARM-VAN DAM, J. - Nauta, R.R. (eds.), The Poetry of Statius, Leiden - Boston, Brill, pp.129-141.

JACKSON, S. (1997), «Argo: the First Ship?», RhM 140, 249-257. 
Joyce, J.W. (2008), Statius, Thebaid: A Song of Thebes, Ithaca, Cornell University Press.

Legras, L. (1905), Étude sur la Thébaïde de Stace, París, Société Nouvelle de Librairie et d'Édition.

Lloyd-Jones, J. (1973), The Justice of Zeus, Berkeley, University of California Press.

LYNE, R.O.A.M. (1987), Further Voices in Vergil's Aeneid, Oxford, Clarendon Press.

Mack, S. (1978), Patterns of Time in Vergil, Hamden, Connecticut, Archon Books.

Magris, A. (1985), L'idea di destino nel pensiero antico, Udine, Del Bianco.

Manuwald, G. (1999), Die Cyzicus-Episode und ihre Funktion in den Argonautica des Valerius Flaccus, Göttingen, Vandenhoeck - Ruprecht.

Micozzi, L. (2010), Stazio. Tebaide, Milano, Arnoldo Mondadori Editore.

Mozley, J.H. (1928), Statius. Thebaid. Achilleid, Cambridge (MA) - Londres, Harvard University Press.

NüNLIST, R. (2007), «Hesiod», en DE JonG, I.J.F. - NüNLIST, R. (eds.), Time in Ancient Greek Literature. Studies in Ancient Grek Narrative, vol. 2, Leiden, Brill, pp.39-52.

O'Hara, J. (1990), Death and the Optimistic Prophecy in Vergil's Aeneid, Princeton, Princeton University Press.

O’Hara, J. (2007), Inconsistency in Roman Epic. Studies in Catullus, Lucretius, Vergil, Ovid and Lucan, Cambridge, Cambridge University Press.

Parry, A. (1963), «The Two Voices of Virgil's Aeneid», Arion 2, 66-80.

Putnam, M. (1965), The Poetry of the Aeneid. Four Studies in Imaginative Unity and Design, Harvard, Harvard University Press.

RAmelLI, I. (1999), «La concezione del divino in Stazio e la conversione del poeta secondo Dante», Gerion 17, 417-432.

REITZ, C. (2012), «Vocem Fata sequuntur: Entscheidungsfindung und epische Konvention in der flavischen Epik», en BAIER, TH. (ed.), Götter und menschliche Willensfreiheit. Von Lucan bis Silius Italicus, München, Verlag C.H. Beck, pp.29-42.

Río Torres-Murciano, A. (2010), «El designio de Júpiter en Valerio Flaco. Providencia, historia y tradición literaria», $C F C(L)$ 30.1, 131-163.

Río Torres-Murciano, A. (2011), El restablecimiento de la causalidad épica en el libro I de las Argonáuticas de Valerio Flaco, Saarbrücken, Editorial Académica Española-Lambert Academic Publishing.

Ripoll, F. (1998), La morale heroique dans les epopees latines d'epoque flavienne. tradition et innovation, Louvain - París, Peeters.

Santamaría Álvarez, M.A. (2015), «El ascenso de Zeus al poder en la Teogonía de Hesiodo y en el poema órfico del papiro de Derveni», Ianua Classicorum. Temas y formas del Mundo Clásico, vol. 3, Madrid, Ediciones Clásicas, 63-70.

Schackleton Bailey, D.R. (2003), Statius. Thebaid, 2 vols., Cambridge (MA), Harvard University Press.

Schetter, W. (1960), Untersuchungen zur epischen Kunst des Statius, Wiesbaden, Otto Harrassowitz.

Schmidt, E.A. (2001), «The Meaning of Vergil's Aeneid: American and German Approaches», CW 94, 145-171.

Setaioli, A. (2006-2007), «Seneca and the Divine: Stoic Tradition and Personal Developments», IJCT 13, 333-368. 
SmolenaArs, J.J.L. (2008), «Statius, Theb. 1.72: Is Jocasta Dead or Alive? The Tradition of Jocasta' Suicide in Greek and Roman Drama and in Statius' Thebaid», en SMOLENAARS, J.J.L. - HARM-VAN DAM, J. - NAUTA, R.R. (eds.), The Poetry of Statius, Leiden - Boston, Brill, pp.215-238.

SniJder, H. (1968), P. Papinius Statius, Thebaid. A Commentary on Book III, Amsterdam, A.M. Hakkert.

Stover, T. (2012), Epic and Empire in Vespasianic Rome: A New Reading of Valerius Flaccus, Oxford, Oxford University Press.

Thomas, R.F. (1999), Reading Virgil and His Texts: Studies in Intertextuality, Ann Arbor, University of Michigan Press.

Thuile, W. (1980), Furiae in der nachklassischen Epik. Untersuchungen zu Valerius Flaccus' Argonautica, Papinius Statius'Thebais und Silius Italicus'Punica, Innsbruck (diss.).

VeninI, P. (1961), «Studi sulla Tebaide di Stazio. La composizione», RIL 95, 55-88.

Vessey, D.W.T.C. (1973), Statius and the Thebaid, Cambridge, Cambridge University Press.

Wacht, M. (1991), Jupiters Weltenplan im Epos des Valerius Flaccus, Stuttgart, F. Steiner.

WeBer, C. (1983), «Two Chronological Contradictions in Catullus 64», TAPA 113, 263-271.

Wecowski, M. (2012), «Can Zeus be deceived? The Mekone episode (Hes.Theog.535-561) between Theodicy and Power-Politics», Klio 94, 45-54.

WheEler, S.M. (1999), A Discourse of Wonders: Audience and Performance in Ovid's Metamorphoses, Philadelphia, University of Pennsylvania Press.

Zissos, A. - Gildenhard, I. (1999), «Problems of Time in Metamorphoses 2», en HARdie, P. BARChIESI, A. - HInds, S. (eds.), Ovidian Transformations: Essays on the Metamorphoses and its Reception, Cambridge, Cambridge Philological Society, pp.31-47. 